Author(s):

M. Laura Angelini , Universidad Católica de Valencia 'San Vicente Mártir'.

Volume

9 Editor(s): Amy Lee, Rhiannon D. Williams ISBN: 978-1-78714-155-

1 eISBN: 978-1-78714-154-4

Citation:

M. Laura Angelini , (2017), Mindful Global Citizenship through Simulations in Higher Education, in Amy Lee, Rhiannon D. Williams (ed.) Engaging

Dissonance: Developing Mindful Global Citizenship in Higher Education

(Innovations in Higher EducationTeaching and Learning, Volume 9) Emerald

Publishing Limited, pp.157 - 171

DOI

10.1108/S2055-364120170000009008

\title{
Mindful global citizenship through simulations in Higher Education
}

\begin{abstract}
This chapter delves into the design of simulations based on literature that can be taught in secondary school. The main objective of the present fieldwork is to determine whether designing simulations is effective in introducing teacher trainees to the use of simulations in secondary education and build mindful global awareness over the issue of human rights. To achieve this, the flipped learning model is followed in which literary pieces and videos are read and analyzed on the part of the teacher trainees outside of class whereas practice, discussion and simulation design are done in class. The findings of the qualitative analysis of postgraduate students' perceptions are presented. Results show that the postgraduate students participating in the design of simulations based on reading texts on human rights find simulations as powerful tools to promote human rights and social consciousness.
\end{abstract}

\section{Introduction}

We may sustain that as a global community we can congratulate ourselves for the progress that has taken place in relation to human rights over the last century. For decades there have been large gains in the matter from governments, national and international organizations, civil society, media, and education. Indicators of the importance of human rights include the abrupt growth in the number of human rights 
organizations and the vast reporting of human rights news across the world since the 1980s. Additional evidence of the mounting progression in the acknowledgment of human rights as a concept is the existence of 25 international treaties on human rights signed since 1926 (Ilgen, 2003). The fluid connection between countries is leading to the identification of shared problems as well as shared solutions. We can no longer speak about national responsibilities only. Global issues and global citizenship are at stake. But what does being global imply? How can education contribute to enhancing global mindfulness? What obstacles and challenges do educators face?

To be a global citizen implies to be part of an emerging world community (Nussbaum, 2006; Peckaski-McLennan, 2008). Being global has to be understood as being actively involved in building these values across communities and broadening the nation-culture perspective to a global one (Stromquist \& Monkman, 2014; Arizpe, 2015). A global citizen must address global problems; participate in the decision-making processes and negotiations of organizations; adopt and promote changes in behavior that help protect the Earth's environment, animals, and human beings; and contribute to world-wide humanitarian relief works; among others (Cogan, 1997).

UNESCO's Teaching and Learning for a Sustainable Future, a multimedia program for teachers, posts the following question: 'What can you as a teacher do to encourage student involvement and participation in active citizenship in your institution'? ${ }^{1}$ Can educators, from their own subjects, contribute through class activities and content selection to arise awareness over the issue of human rights and global citizenship? If we educators stop to think about this thoroughly and take action, our contribution would have a great impact on society. Can we help our learners reflect upon issues such as 'our society tolerates social marginalization, expulsion, and reclusion'; 'our society mostly sees education from an instrumentalist point of view'; or 'our society emphasizes individual benefits over collective ones'?

Education itself is a fundamental human right and a noteworthy factor in the development of children, communities, and countries. To cite an example, in 2006 the Spanish Educational System introduces the subject 'Education for citizenship and Human Rights' in primary and secondary school. Together with this, emphasis is put on the development of the social competence that is a cross-curricular competence. In 2008, a Plan for Human Rights issued by the Government, and subsequent plans designed by some autonomous communities in Spain, fosters the integration of human rights in schools in line with the demands of international organizations ${ }^{2}$.

However, little progress has been made due to controversy and rejection from some sectors that pointed out that the State should not assume the moral education of its citizens. In 2012, the Government of Spain decides the disposal of the subject of Education for Citizenship and Human Rights and replaces it by the Civic and Constitutional Education, whose contents were this time supposedly free from controversy and ideological indoctrination.

According to Amnesty International, human rights education must constitute a high priority in the curricula nowadays no matter the political wing ruling the country. It is a

\footnotetext{
${ }^{1}$ UNESCO, Teaching and Learning for a Sustainable Future, retrieved from: http://www.unesco.org/education/tlsf/mods/theme_b/mod07.html

${ }^{2}$ Amnesty International, retrieved from:

https://www.es.amnesty.org/uploads/media/Informe_Educacion_par_la_Ciudadania.pdf
} 
must to guarantee respectful and plural environments in education and society. To achieve this, Amnesty International urges to agree on a compulsory subject on human rights and citizenship in primary and secondary education in Spain; introduce a compulsory subject in teaching degrees in higher education and in post-graduate degrees on education.

In line with this, the present chapter argues that in order to realize the educational policies, it is necessary to implement a methodological shift in how we prepare future teachers. Teaching degrees should draw the strands of development global citizenship under a common framework in which the local and the global become intertwined and interconnected. At university, prospective teachers should experience and learn to develop curriculum and learning activities that focus on the development of global citizenship and empathy. In this way, they will be more prepared to respond to multicultural classrooms so frequent today.

The chapter looks at a postgraduate course for teachers of English as a foreign language in secondary school in which teacher trainees $(N: 103)$ were introduced to simulations through the use of flipped learning and simulation design in an attempt to develop social awareness, empathy, and an understanding of global citizenship. Simulation has been defined as "the artificial representation of a real-world process to achieve educational goals via experimental learning" (Flanagan \& Nestel, 2004 in Al-Elq, 2010). Students had their degrees in EFL and had teaching experience as private tutors or as academy teachers. Data collection belongs to three different academic courses $(2012,2013$, and 2014). Participants in the study were in the first year of a postgraduate course that would enable them to work in state secondary schools and in state-subsidized schools in Spain. Teacher trainees learned to design simulation scenarios from the literature provided. Through simulation design, the students could get a clear glimpse of simulations potential to enhance human rights and to develop global mindfulness and empathy.

This chapter, thus, seeks to construct the argument that a methodological shift more focused on students and the development of global citizenship, empathy, and transformational social visions help prepare innovative, sensitive professionals that can respond to today's demands in education. Students respond to the open-ended question: what are your perceptions about the course? Obstacles and challenges are identified and the findings of a qualitative analysis of postgraduate students' responses are presented and analyzed.

But what do we mean by simulation? A simulation refers to an event in which the participants have duties and sufficient key information about the problem to carry out these duties without play acting or inventing key facts (Jones, 1995, p. 18). Thus, we find that in a simulation there is a representation of a system with key information to carry out tasks and solve the problem (for a more detailed discussion on the taxonomy of simulations, see Klabbers, 2009). Simulations provide opportunities for active participation to develop interactive and communication skills, and link knowledge and theory to application (Hertel and Millis, 2002).With simulations, students are introduced to a reality in which they have to find solutions to certain problems. To do this, they must learn about the topic, elaborate proposals, negotiate viewpoints, and make decisions (Angelini, García-Carbonell \& Martínez-Alzamora, 2015). Participants are exposed to reading material, audio-visual resources, and recent news available on the web to familiarize with the topics (Crookall \& Oxford, 1990; Angelini, 2012, 2016; 
García-Carbonell \& Watts, 2012; Angelini \& García-Carbonell, 2014, Watts, García-

Carbonell \& Angelini, 2015). It is paramount to instill in students ethical

responsibilities and to use simulation scenarios as the basic tool to develop a global mindset (Habermas, 1992).

\section{Implications and challenges in higher education}

Higher education in Spain confronts several challenges nowadays, including diversity in approaches to teaching and learning, concerns about citizenship and civic education, inclusion and attention to diversity, to name a few. In terms of content, it is easily appreciated the predominance of economic interests in the curricula which lifts languages, science and technology to the top of the list, being civic education relegated (Hampton \& Demeure-Ahearne, 2016). In the light of the current situation, what are the challenges to the attainment of a mindful global citizenship in higher education in Spain? It seems it is our responsibility as professionals of education to design programs and courses to foster these changes (Nunan \& Lamb, 2000; Shephard, 2008; Forehand, 2010, Zsabo, 2015).

Thus, in our official postgraduate teacher training program at the Catholic University of Valencia, the subject 'Pedagogical Resources for Teaching EFL and Literature in Secondary School' promotes the use of flipped classroom, learning corners, and simulations to accomplish several objectives: to promote human rights through literature, to develop empathy towards others' realities, and to develop a caring global citizenship. We strongly believe that it is crucial to start paying attention to what it is there in our classrooms. More and more we find multicultural classrooms and neighborhoods with plenty of children, adolescents and adults from abroad, many of whom from unprivileged realities. Our classrooms should turn into environments open to dialogue, integration and coexistence rather than marginalization. The learning and sharing that occur inside the classroom spreads outside - to the school community, families, and to the wider community, too. This is why human rights education in the classroom is so important.

During the semester, learners are expected to (a) create simulation scenarios based on literature that delves into human rights; (b) help build the affective dimensions of learning and empathy through daily teaching; and (c) carry out in-classroom research through the integration of different pedagogical models.

\section{Pedagogical Resources for Teaching EFL and Literature in Secondary School}

A group of post-graduate students $(\mathrm{N}=103)$ went through scenario design in the official postgraduate course entitled 'Pedagogical Resources for Teaching EFL and Literature in Secondary School at Catholic University of Valencia San Vicente Mártir. Students were all teacher trainees receiving instruction to teach English and literature in secondary school. Data were collected during three consecutive courses with different students in each course. 
Table 1

Teacher trainees enrolled in a postgraduate course per year. Teacher trainees receive instruction to teach English and literature to secondary school students.

\begin{tabular}{|l|l|l|l|l|}
\hline Year course & $\mathbf{2 0 1 2}$ & $\mathbf{2 0 1 3}$ & $\mathbf{2 0 1 4}$ & Total N \\
\cline { 1 - 3 } $\begin{array}{l}\text { Postgraduate } \\
\text { students }\end{array}$ & $\mathrm{N}=34$ & $\mathrm{~N}=30$ & $\mathrm{~N}=39$ & N=103 \\
\hline
\end{tabular}

\section{Outside of class}

Students, following the flipped classroom model, prepared for class sessions by learning about simulation theory and design. Flipped classroom or Flipped Learning is a pedagogical approach in which there is a reversal of traditional teaching. Students gain first exposure to new material outside of class, usually via reading or lecture videos; and during class time they apply concepts and notions in the subject matter through strategies such as problem-solving, discussion or debates. Through the implementation of the flipped classroom, we seek to enhance learners' autonomy by doing the theoretical work out of the class (Bergmann, 2013; Bergmann, Overmyer \& Wilie, 2013). Learners read the texts and watched some recommended videos on the issues present in the pieces of literature to get deeper insights on the portrayed realities, most depicting the deprivation of human rights. Some of the material students were exposed to were: A Private Experience by Chimamanda Ngozi Adichie, some scenes from the film based on The Grapes of Wrath by John Steinbeck, some fragments from Things That Fall Apart by Chinua Achebe, A Long Walk to Water by Linda Sue Park and Kay Kennedy's poem Words Hurt, among others.

\section{In class}

Conversely, in class, three learning stations with different tasks were created and different simulation scenarios analyzed to get the gist of scenarios structure and design. It is important to remark that students had to read about simulation structure and design outside of class to analyze its parts in class with their teams as seen in fig. 1 . The International Communication \& Negotiation Simulations (ICONS) from the University of Maryland serve as clear examples of simulations for our students.
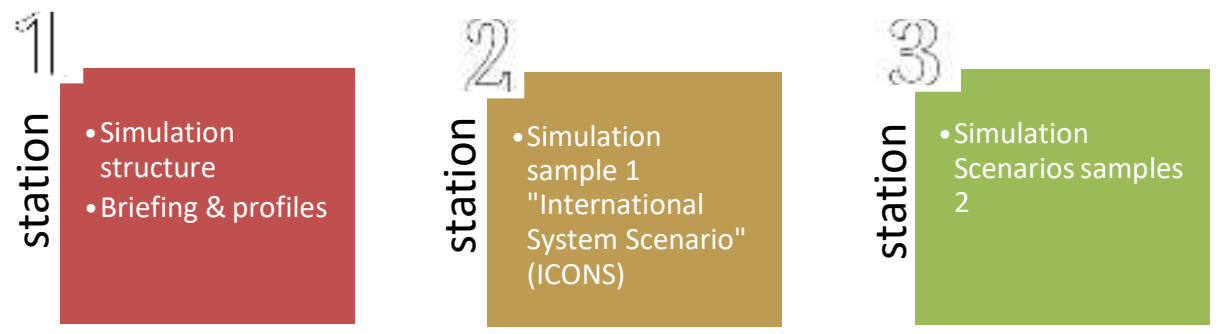

Figure 1. Learning stations to assimilate simulation structure and some simulation samples.

These activities enabled the learners to create their own scenarios and simulations based on literature that can be taught in secondary education. During the courses, in teams of up to five members, students worked together on the analysis of sample scenarios to be able to design their own scenarios on the topic of human rights. Teacher trainees started discussing simulation structure in station 1. It was fundamental that teacher trainees assimilate simulation structure and individual profiles as the success of a simulation, to 
a great extent, depends on how well the structure and profiles are defined. Teacher trainees could only move to station 2 and 3 once they had complied with an in-depth analysis of the structure of a simulation in station 1 . In the subsequent stations, teacher trainees had to analyze samples of simulations that may inspire them to create their own. After going through the three stations, teacher trainees started planning their own simulation with their teams. Simulation scenarios were based on themes from the literary pieces provided. Our attempt was to bring about some controversial issues of social impact, which, in many cases, are not addressed in education. The goal was to help learners become more aware of their affect, building an 'affective mirror' that encourages reflection upon learners' own feelings and their influence on the learning experience (Picard, Papert, Bender, Blumberg, Breazeal, Cavallo, ... \& Strohecker, 2004; Hazelkorn, 2015). Creating simulations challenged students to reflect on global issues and to develop a sense of global awareness. The ultimate goal was to develop scenarios, profiles, pre-action protocols, and debriefing instructions.

To accomplish this, teacher trainees had to complete the following in and out of class. 


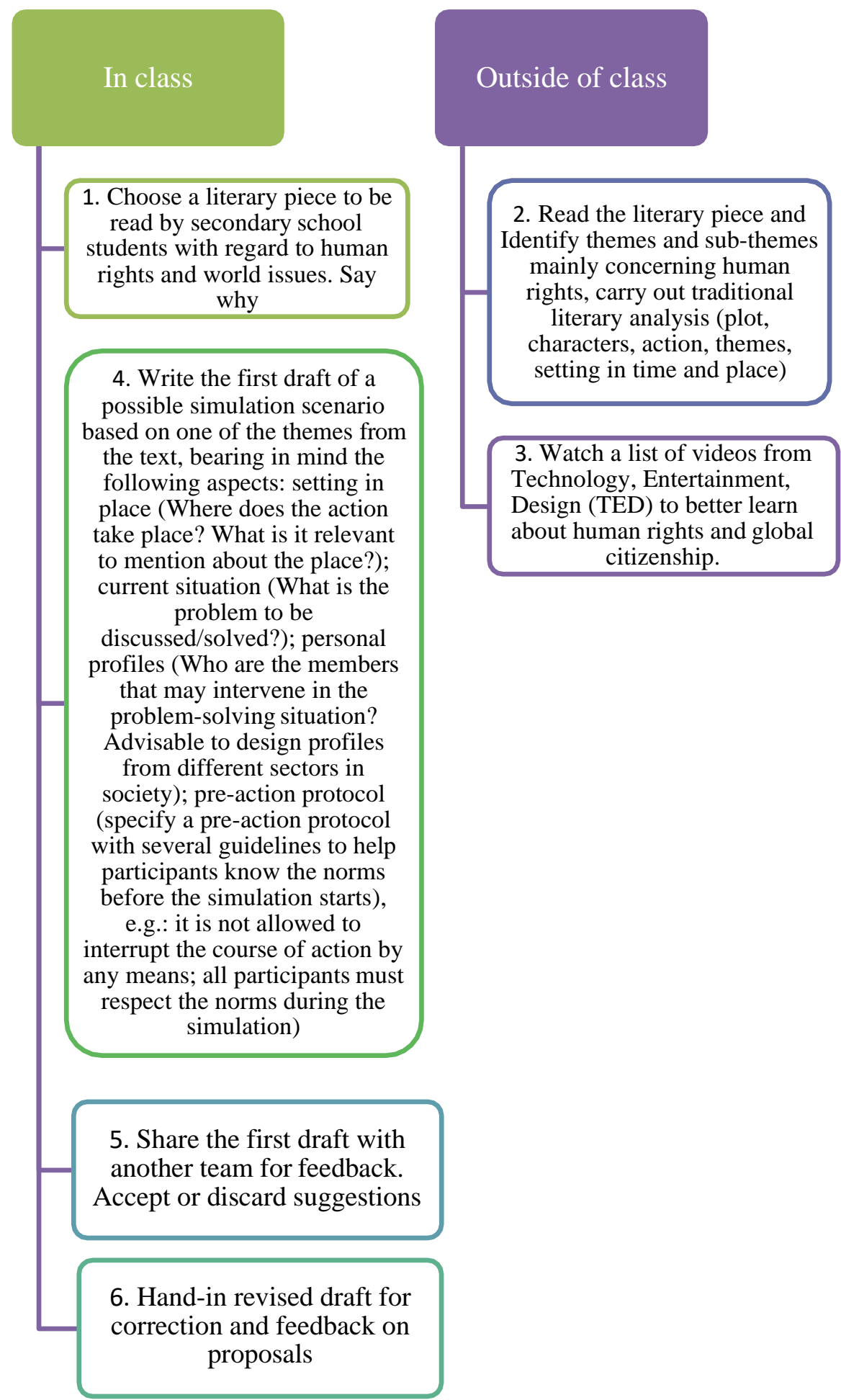

Figure 2. Scenario design procedure to be followed in and out of class.

To better learn about human rights and global mindfulness, a list of videos from Technology, Entertainment, Design (TED) was given to the students to be watched out of the class. This material was mainly about the importance of including human rights in daily teaching and developing world mindfulness. By watching these videos, students could learn about social injustice, prejudices, individual struggles to community integration, among others. They were chosen to help students better create their simulation scenarios and individual profiles by broadening their scope of understanding. 
Team work and collaborative learning were fostered by working in learning stations (fig. 1) on simulation design. By doing collaborative work intergroup, participants received feedback on their proposals by their peers. Lessons were transformed into learning communities in which students exchanged points of view on their scenarios. Thus, the final project consisted of creating a scenario by:

- picking a literary piece and identifying themes;

- choosing one theme to base the simulation scenario on;

- creating a context and briefing description of the simulation;

- identifying a set of goals and individual profiles.

Two samples of scenarios are provided below.

\section{Scenario 1}

Context: This simulation is intended to be used with secondary school students, intermediate level of English, no special educational needs.

Literary Piece: 'Things Fall Apart' by Chinua Achebe (Fragment). Two main themes to design the scenario are the economy activation and women rights.

Briefing: 'Oktopus' is an international philanthropic fashion company. It encourages fair trade all over Langaria, a country in Manzovia. The mission is to secure long-term production by giving the opportunity to mostly women to work, study, design and sustain their families. Unfortunately, sales have dropped dramatically, heavy rain has ruined cotton crops in most of the region and an important number of women have been denied the right to work after some time working for the company. This has caused delays in manufacturing and deliveries to most subsidiaries in Langaria.

Goals:

1. Find cotton suppliers somewhere else in order to continue the production and negotiate costs;

2. Think of some strategies to activate sales;

3. Think of some strategies to bring back women's rights to work.

Roles: A committee has been created to put an end to this situation. Committee: an economist, a sociologist, a NGO member, a politician, and a social worker.

\section{Scenario 2}

Context: This simulation can be used with secondary school students in the early courses, pre-intermediate or intermediate level of English, no special educational needs.

Literary Piece: this simulation has been inspired by 'The Grapes of Wrath' by John Steinbeck. Themes: poverty and racial discrimination

Briefing: Things are going well in Landisus for once. Landisus has been a forgotten region for many years. Noone can explain how it survived being surrounded by towns and industrial cities where a peaceful coexistence could not be granted. In the middle of nowhere, with no easy access by road, now Landisus is alive with the coming of new factories and hundreds of workers of many different nationalities who are planning to settle there. As the surrounding regions, Landisus may run the same fate if racial and economic circumstances keep people separate. So now, as many workers find it necessary to live near their work, they are asking the Government for some solution to prevent discrimination. Landisus Government have to organize the region to ensure peace and justice among its inhabitants. 


\section{Goals:}

1. Think of measures to be taken to guarantee that the rapid development of the region is complemented by effectiveness, accountability and transparency at all levels;

2. Think of ideas to best distribute part of the incomes from the production;

3. Think of strategies to end with racial discrimination.

Roles: The Higher Commission is made up of a landowner, a tenant, the

Governor, the priest.

Postgraduate students, after designing and presenting their simulations, were asked to write about this teaching proposal answering the question: What are your views on the course? Written responses $(\mathrm{N}=103)$ to the question were uploaded onto the university intranet platform and later extracted to be analyzed.

\section{Learner's perceptions}

The students' perceptions on the course yielded three categories, namely: simulation scenarios as a teaching-learning tool, literature to promote human rights and students' mindful global citizenship.

As for the first category, simulation scenarios as a teaching-learning tool, most students were positive about designing simulation scenarios. They found it quite innovative. Many sustained that through designing scenarios they have broadened their perspectives of literature in class. For some, the issues addressed in some of the texts were not new, as hunger, deprivation of education, child labor, among many others. As they stated, alarming news on human rights abuse are widespread nowadays everywhere.

I find it really dynamic and I would like to know more about it. I see a great potential in the method and also teachers may benefit from this to create more active classes. (L 2)

Some topics are not actually new and students are familiar with them in one way or in another. Through simulations our students will surely be able to connect with reality in some way I think I will use with my students as what they demand is more real practice rather than theoretical classes. (L 31)

In language classes we all want our students to speak. Language knowledge is a barrier in countries like this one where English is a foreign language. I personally find that through simulations students can learn more about the world at the time they receive input of real language and use the language to communicate purposefully. (L 44)

In the second category, literature to enhance human rights, participants approved of working in a worry-free environment in which they could speak their minds over controversial issues. In most cases, literature is treated in secondary school in the conventional way. By designing a simulation, teacher trainees discovered that they could veer from the text and gain a much wider understanding of social issues due to the 
interactive value of the simulation. Team-work fostered interpersonal relationships and teacher trainees shared viewpoints with others. Agreement on some issues was difficult to reach by only a few participants because of the interference of some prejudices against race, religion, social status, gender, etc., which led to confrontation.

I really foresee the potential of the simulation and how my own students may benefit from it and become more conscious of social problems. [...] Communication is definitely fostered and understanding of others' realities is central to build a civilized society. (L 14)

I found it rather hard as we had to defend some our ideas. Moral issues and diversity of opinions led to some misunderstandings. I felt bad about that though I experienced some catharsis and real immersion in the discussion; needless to say that I've questioned my own position about certain topics as well. (L 29)

I liked the fact that in class I got the opportunity to know what others thought about some important issues. I was very surprised to know that we all have some kind of prejudices against other people. I had not stopped to think about this until we had to design a scenario in which social justice and social integration had to be fostered. (L 31)

Most teacher trainees considered the experience enriching. The literary pieces treated in class helped participants gain insights into human rights as well as their own feelings towards the issue.

The third category students' mindful global citizenship, most students found they had learned more about themselves and their position with respect to several issues present in the literature as women's discrimination, child labor, torture, and the oppressive global economy, as well as their own responsibilities as citizens to take a stand in views of human rights deprivation.

I will use simulations selecting the material to be discussed as my students are 13-14 years old. I'm afraid maturity to fully understand the problematic issues is necessary. All the same, empathy development will be a must in the course syllabus next year. (L 16)

I find extremely important to deal with global issues in class. We should find real topics and teach our students to be better citizens by showing interest in world issues and participate actively in society. As teachers, we should mind this. (L 49)

I see I may work with them in my school and start building on empathy and global citizenship, both so necessary nowadays. (L 96)

A powerful idea seemed to have gained approval among the post graduate students. One said: 'I do not want to carry out the kind of teaching I have always rejected'. 
The traditional scheme of education can be beyond the reach of the experience and maturity the young learners already possess. Learning here means acquisition of what already is incorporated in books and in the heads of the elders. Therefore, rejection seems to be the natural outcome from the learners.

The key to education today must be in line with participation, transformational experiences that lead students to become better citizens. I believe this can be done with every single subject. No need for memorization and final global exam. We shouldn't lose sight of the process. (L 89)

Most participants acknowledged the power of simulations as a transformational tool in education due to the possibility to mirror other people's feelings and gain profound perceptions of the human condition, thus awakening empathy and building on mindful citizenship.

\section{Conclusions}

Results of the qualitative analysis of teacher trainees' perceptions revealed the participants' approval of several aspects concerning our postgraduate course. Firstly, introducing literature that may enhance awareness of the issue of human rights is highly accepted by the majority of the teacher trainees. In times of injustice, social unrest and human values decline, it seems necessary to re-direct teaching through thoughtprovoking activities in order to build critical thinking and empathy. Additionally, some of the participants who work in some schools indicated the need to re-direct their course guides towards a more social-transformational design. They understood there was an added layer of responsibility from the school to society. As professionals in education, the postgraduate students agreed that they had to promote social or community values in some ways, being simulations a pedagogical alternative unknown to them. Secondly, postgraduate students understood the notion of global belonging, particularly relevant in this territorial fragmented European reality. They found a great potential in simulations to enhance global citizenship as they themselves were immersed in a reality in which they had to interact, exchange ideas and make decisions. By designing simulations, teacher trainees placed themselves in a two-fold role; as a teacher and as a student. As teachers, they had to carefully find the reading material, identify the topics, and create the scenario and all the elements of a simulation. As students, they analyzed their scenarios and profiles and their peers' to determine their applicability in high school classrooms. Finally, this initiative to first make teachers aware of their responsibility once in a school classroom and second, to carry out a sensible and true-to-life teaching advocating values to make a better society must be the cornerstone of all higher education degrees. So, the question here is, why not turning our lessons into fruitful communicative learning environments by using simulations? This chapter is a first step into bringing together personal teaching experience to construct a science of mindful global learning. 


\section{References}

Al-Elq, A. H. (2010). Simulation-based medical teaching and learning. Journal of Family \& Community Medicine, 17, 35-40.

Angelini, M. L. (2012). Simulation and Gaming in the Development of Production Skills in English. Department of Applied Linguistics, Universitat Politècnica de València. Valencia: June 2012. PhD. Dissertation.

Angelini, M. L \& García-Carbonell, A (2014). Análisis cualitativo sobre la simulación telemática como estrategia para el aprendizaje de lenguas. RIE Revista Iberoamericana de Educación, 64(2). Retrieved from: https://riunet.upv.es/handle/10251/52704

Angelini, M. L, García-Carbonell, A, Martínez-Alzamora, N. (2015). Estudio cualitativo sobre la simulación y juego en la producción oral en lengua inglesa. REDU. Revista de Docencia Universitaria 13(2). Retrieved from: https://dialnet.unirioja.es/servlet/articulo? codigo $=5210435$

Angelini, M. L. (2016). Integration of the pedagogical models "Simulation" and "Flipped Classroom" in teacher instruction, Sage Open. doi: $10.1177 / 2158244016636430$

Arizpe, L. (2015). Cultural diversity as a source of creativity for globalization. In Culture, Diversity and Heritage: Major Studies (pp. 83-90). Springer International Publishing. doi: 10.10007/978-3-319-13811-4_6

Bergmann, J. (2013). The flipped classroom: A student's perspective. Retrieved from http://researchnetwork.pearson.com/learning-science-technology/the-flippedclassroom-a-students-perspective

Cogan, J. (1997). Multidimensional citizenship: Education policy for the twenty-first century. Tokyo: Sasakawa Peace Foundation.

Crookall, D., \& Oxford, R. L. (Eds.). (1990). Simulation, gaming, and language learning. New York: Newbury House.

Forehand, M. (2010). Bloom's taxonomy. Emerging perspectives on learning, teaching, and technology, 2(2), 41-47.

García-Carbonell, A. \& Watts, F. (2012). Investigación empírica del aprendizaje con simulación telemática. Revista Iberoamericana de Educación, 59(3), 1-11.

Habermas, J. (1992). Citizenship and national identity: Some reflections on the future of Europe. Praxis International, 12(1), 1-19.

Hampton, C., \& Demeure-Ahearne, A. (2016). From widening horizons to widening participation: Transmitting the experience of global citizenship to the school classroom. Innovative language teaching and learning at university: Enhancing participation and collaboration, 1(1), 95-104. 
Hazelkorn, E. (2015). Rankings and the reshaping of higher education: The battle for world-class excellence. London: Palgrave Macmillan.

Hertel, J. P. \& Millis, B. J. (2002). Using simulations to promote learning in higher education: An introduction. Virginia: Stylus Publishing.

Ilgen, T. (2003). Reconfigured sovereignty. Multi-layered governance in the global age. U.K.: Ashgate.

Jones, K. (1995). Simulations. A handbook for teachers and trainers. London: Nichols Publishing Company.

Klabbers, J. H. (2009). Terminological ambiguity: Game and simulation. Simulation Gaming, (40), 446-463.

Nunan, D. \& Lamb, C. (2000). The self-directed teacher. Managing the learning process. UK: Cambridge Language Education.

Nussbaum, M. (2006). Frontiers of justice. Disability, nationality, species membership. Cambridge, MA: Harvard University Press.

Peckaski-McLennan, D. M. (2008). The benefits of using socio-drama in the elementary classroom: Promoting caring relationships among educators and students. Early childhood education journal, 35(5), 451-456.

Picard, R. W., Papert, S., Bender, W., Blumberg, B., Breazeal, C., Cavallo, D., ... \& Strohecker, C. (2004). Affective learning - a manifesto. BT Technology Journal, 22(4), 253-269.

Shephard, K. (2008). Higher education for sustainability: seeking affective learning outcomes. International Journal of Sustainability in Higher Education, 9 (1), 87 $-98$.

Stromquist, N. P., \& Monkman, K. (Eds.). (2014). Globalization and education: Integration and contestation across cultures. N.Y: Rowman \&Littlefield.

Szabo, S. (2015). Missing in Action: Good citizenship and good learning. International Journal for Professional Educators. Retrieved from https://www.questia.com/library/journal/1P3-3971765301/missing-in-actiongood-citizenship-and-good-learning

Watts, F., García-Carbonell, A., Angelini, M. L (2015). The flipped classroom and simulation and gaming in teacher training. Proceedings of the $9^{\text {th }}$ International Multi-Conference on Society, Cybernetics and Informatics. Orlando: FL: International Institute of Informatics and Systemics, 1(1), 185-189. 